\title{
Self-oscillating Chemoelectrical Interface of Solution-gated Ion-sensitive Field-effect Transistor Based on Belousov-zhabotinsky Reaction
}

Toshiya Sakata ( $\sim$ sakata@biofet.t.u-tokyo.ac.jp )

The University of Tokyo

Shoichi Nishitani

The University of Tokyo

Yusuke Yasuoka

The University of Tokyo

Shogo Himori

The University of Tokyo

Kenta Homma

The University of Tokyo

\section{Tsukuru Masuda}

The University of Tokyo

Aya Mizutani Akimoto

The University of Tokyo

Kazuaki Sawada

Toyohashi University of Technology

Ryo Yoshida

The University of Tokyo

\section{Research Article}

Keywords: Belousov-Zhabotinsky (BZ) reaction, ion-sensitive field-effect transistor (ISFET), pH oscillation, self-oscillating polymer, chemoelectrical interface

Posted Date: December 1st, 2021

DOI: https://doi.org/10.21203/rs.3.rs-1110032/v1

License: (1) (1) This work is licensed under a Creative Commons Attribution 4.0 International License.

Read Full License 
Version of Record: A version of this preprint was published at Scientific Reports on February 22nd, 2022. See the published version at https://doi.org/10.1038/s41598-022-06964-4. 


\section{Self-oscillating chemoelectrical interface of solution-gated ion-sensitive field-effect}

\section{transistor based on Belousov-Zhabotinsky reaction}

Toshiya Sakata, ${ }^{*}$ Shoichi Nishitani, ${ }^{1}$ Yusuke Yasuoka, ${ }^{1}$ Shogo Himori, ${ }^{1}$ Kenta Homma, ${ }^{1}$ Tsukuru Masuda, ${ }^{2}$ Aya Mizutani Akimoto, ${ }^{1}$ Kazuaki Sawada,${ }^{3}$ and Ryo Yoshida ${ }^{1}$

${ }^{1}$ Department of Materials Engineering, School of Engineering, The University of Tokyo, 7-31 Hongo, Bunkyo-ku, Tokyo 113-8656, Japan

${ }^{2}$ Department of Bioengineering, School of Engineering, The University of Tokyo, 7-3-1 Hongo, Bunkyo-ku, Tokyo 113-8656, Japan

${ }^{3}$ Department of Electrical and Electronic Information Engineering, Toyohashi University of Technology, Tempaku-cho, Toyohashi 441-8580, Japan

*Corresponding author. E-mail: sakata@biofet.t.u-tokyo.ac.jp

CORRESPONDING AUTHOR FOOTNOTE: Affiliation; Department of Materials Engineering, School of Engineering, The University of Tokyo, 7-3-1 Hongo, Bunkyo-ku, Tokyo 113-8656, Japan, TEL; +81-3-5841-1842, FAX; +81-3-5841-1842 


\section{Abstract}

The Belousov-Zhabotinsky (BZ) self-oscillation reaction is an important chemical model to elucidate nonequilibrium chemistry in an open system. However, there are only a few studies on the electrical behavior of $\mathrm{pH}$ oscillation induced by the $\mathrm{BZ}$ reaction, although numerous studies have been carried out to investigate the mechanisms by which the BZ reaction interacts with redox reactions, which results in potential changes. Needless to say, the electrical characteristic of a self-oscillating polymer gel driven by the BZ reaction has not been clarified. On the other hand, a solution-gated ion-sensitive field-effect transistor (ISFET) has a superior ability to detect ionic charges and includes capacitive membranes on the gate electrode. In this study, we carried out the electrical monitoring of self-oscillation behaviors at the chemoelectrical interface based on the BZ reaction using ISFET sensors, focusing on the $\mathrm{pH}$ oscillation and the electrical dynamics of the self-oscillating polymer brush. The $\mathrm{pH}$ oscillation induced by the BZ reaction is not only electrically observed using the ISFET sensor, the electrical signals of which results from the interfacial potential between the solution and the gate insulator, but also visualized using a large-scale and high-density ISFET sensor. Moreover, the $N$-isopropylacrylamide (NIPAAm)-based self-oscillating polymer brush with $\mathrm{Ru}(\mathrm{bpy})_{3}$ as a catalyst clearly shows a periodic electrical response based on the swelling-deswelling behavior caused by the BZ reaction on the gate insulator of the ISFET sensor. Thus, the elucidation of the electrical self-oscillation behaviors induced by the BZ reaction using the ISFET sensor provides a solution to the problems of nonequilibrium chemistry.

KEYWORDS: Belousov-Zhabotinsky (BZ) reaction; ion-sensitive field-effect transistor (ISFET); pH oscillation; self-oscillating polymer; chemoelectrical interface 


\section{Introduction}

As a chemical model of the tricarboxylic acid cycle (TCA), the Belousov-Zhabotinsky (BZ) reaction is well known to show a chemical self-oscillation behavior that is not dominated by equilibrium thermodynamic behavior (nonequilibrium chemistry). ${ }^{1-3}$ In general, a reactant changes to a reaction product in one direction or in an equilibrium state through a chemical reaction. However, a self-oscillation reaction can be chemically induced under an optimum condition, where the reaction products (intermediates) are periodically utilized as the reactants. In the BZ reaction, organic substances such as malonic acid reduces metallic catalysts (e.g., $\mathrm{Ce}^{4+}, \mathrm{Fe}($ phen $) 3^{3+}, \mathrm{Ru}($ bpy $\left.) 3^{3+}\right)$, and then their reduced catalysts are oxidized by oxidants such as bromic acid $\left(\mathrm{BrO}_{3}{ }^{-}\right)$in an acid solution, where the cyclic redox reaction spontaneously occurs. When the ruthenium bipyridine complex $\mathrm{Ru}(\mathrm{bpy}) 3^{2+/ 3+}$ is utilized as a metallic catalyst, the cyclic redox reaction is observed from the change in the color of the BZ solution $\left[\mathrm{Ru}(\text { bpy })_{3}{ }^{2+}\right.$ (orange) $\rightleftarrows \mathrm{Ru}(\text { bpy })_{3}{ }^{3+}$ (light green $\left.)+\mathrm{e}^{-}\right] .{ }^{4,5}$ This cyclic redox reaction was also electrochemically monitored using metal electrodes such as Pt and Ag on the basis of the halfcell reaction. ${ }^{6}$ Simultaneously, the concentration of protons, $\left[\mathrm{H}^{+}\right]$, should periodically change in accordance with the $\mathrm{BZ}$ reaction. In fact, there are a few studies in which the change in $\mathrm{pH}$ caused by the $\mathrm{BZ}$ reaction was investigated using ion sensitive electrodes. ${ }^{7,8}$ On the other hand, the changes in the concentrations of catalysts and intermediates such as $\mathrm{Br}^{-}$seemed to have been analyzed without considering the change in $\left[\mathrm{H}^{+}\right](\mathrm{pH})$ in many studies. ${ }^{9-14}$ However, the cyclic behavior of $\mathrm{pH}$ based on the $\mathrm{BZ}$ reaction was not necessarily observed using an ion sensitive array, ${ }^{7}$ nor was it imaged using an ion-sensitive field-effect transistor (ISFET) ${ }^{8}$ which is utilized in this study. Therefore, the monitoring and imaging of the $\mathrm{pH}$ self-oscillation based on the $\mathrm{BZ}$ reaction is valuable for the elucidation of nonequilibrium reactions.

The BZ reaction proceeds in an open and nonlinear chemical reaction system. ${ }^{15,16} \mathrm{~A}$ polymer gel is a cross-linked three-dimensional polymer network that swells upon immersion 
in a solvent, providing an open system for heat and mass transfer. So far, we have found a selfoscillating system in a stimulus-responsive polymer gel based on $N$-isopropylacrylamide (NIPAAm) that is driven by the BZ reaction. In particular, the poly[NIPAAm-co-Ru(bpy) ${ }_{3}$ gel clearly exhibited periodical volume changes (swelling and deswelling) in an aqueous solution containing the reactants of the $\mathrm{BZ}$ reaction, except for the catalyst. ${ }^{5,17}$ This indicates that the chemomechanical self-oscillation of the polymer gel is realized in a closed solution without external stimuli. Therefore, the self-oscillating polymer gel is expected to be applied to the observation of peristatic motions in biological systems and actuators in bioanalytical systems. ${ }^{18-20}$ In addition, the chemomechanical energy derived from the self-oscillating polymer gel may be converted into electrical energy for autonomous sensors when its electrical properties are clarified.

Considering the above, we examined the self-oscillating chemoelectrical interface based on the BZ reaction using a solution-gated ISFET sensor. This sensor was proposed for detecting ions and biomolecules in biological environments. ${ }^{21,22}$ In this device, an electrolyte solution induces the interfacial potential between the solution and the gate insulator instead of a metal gate in a metal-oxide-semiconductor (MOS) transistor; this device, however, requires a reference electrode in the solution. The gate insulator is often composed of oxide or nitride membranes such as $\mathrm{Ta}_{2} \mathrm{O}_{5}, \mathrm{Al}_{2} \mathrm{O}_{3}, \mathrm{Si}_{3} \mathrm{~N}_{4}$, and $\mathrm{SiO}_{2}$; therefore, hydroxyl groups at the oxide or nitride surface in the solution undergo the equilibrium reaction with hydrogen ions through protonation $\left(-\mathrm{OH}+\mathrm{H}^{+} \rightleftarrows-\mathrm{OH}_{2}^{+}\right)$and deprotonation $\left(-\mathrm{OH} \rightleftarrows-\mathrm{O}^{-}+\mathrm{H}^{+}\right)$. This is why the change in the surface charge is detected from the change in $\mathrm{pH}$ in accordance with the principle of the field effect. ${ }^{23,24}$ Such ISFET sensors mostly have a silicon substrate, but a variety of semiconducting materials have recently been applied to $\mathrm{pH}$-sensitive ISFET sensors. ${ }^{25,26}$ Moreover, a large-scale and high-density ISFET (arrayed-gate ISFET) sensor has recently been developed with the progress of complementary MOS (CMOS) integrated circuit 
technologies. ${ }^{27-34}$ Using the arrayed-gate ISFET sensor, one can image the change in $\mathrm{pH}$ in the solution by detecting it on each gate insulator, which is called the $\mathrm{pH}$ image sensor. ${ }^{27}$ In a previous paper, an ideal $\mathrm{pH}$ sensitivity of approximately $55 \mathrm{mV} / \mathrm{pH}$, which was near the Nernstian response at the electrolyte solution/gate insulator interface, and a high frame speed of 1933 fps were reported. ${ }^{34}$ Notably, this sensor had the smallest pitch of $2 \mu \mathrm{m}$, which resulted in a high spatial resolution.

In addition, the gate insulator surface of the ISFET sensor was chemically modified to specifically and selectively detect biomolecules and to reduce electrical noise from interfering species. ${ }^{35,36}$ Also, such chemical modifications on the gate insulator surface contributed to the electrical detection of the phase transition (swelling and deswelling) in the poly(NIPAAm) gel. ${ }^{37}$ Therefore, the self-oscillating polymer gel-coated gate ISFET sensor is expected to be used for the electrical monitoring of self-oscillation based on the phase transition on the modified surface, which is driven by the BZ reaction.

In this paper, we report the electrical monitoring of self-oscillation at the chemoelectrical interface based on the BZ reaction using the ISFET sensors, focusing on the $\mathrm{pH}$ oscillation and the electrical dynamics of the self-oscillating polymer brush.

\section{Results and Discussion}

Real-time monitoring of $\mathrm{pH}$ oscillation induced by $\mathrm{BZ}$ reaction with single-gate ISFET sensor

The $\mathrm{Ta}_{2} \mathrm{O}_{5}$ film was used as the gate insulator of the ISFET sensor in this study. The $\mathrm{Ta}_{2} \mathrm{O}_{5}$ surface has hydroxy groups in an electrolyte solution, which shows the equilibrium reaction with hydrogen ions depending on $\mathrm{pH}$. Therefore, the change in potential at the solution/ $\mathrm{Ta}_{2} \mathrm{O}_{5}$ gate insulator interface is electrically output with varying $\mathrm{pHs}$, depending on the Nernstian response $\left(59.2 \mathrm{mV} / \mathrm{pH}\right.$ at $\left.25^{\circ} \mathrm{C}\right)$. The Nernst equation for $\mathrm{pH}$ is shown as equation 1 and strictly 
reflected by the coefficient $[\beta /(\beta+1)]$ with the parameter $\beta$ (equation 2 ):

$$
\begin{gathered}
\varphi_{0}=2.303 \frac{k T}{q}\left(\frac{\beta}{\beta+1}\right)\left(\mathrm{pH}_{\mathrm{pzc}}-\mathrm{pH}\right) \\
\text { with } \beta=\frac{2 q^{2} N_{\mathrm{S}} K_{\mathrm{a}}^{1 / 2}}{k T C_{\mathrm{DL}}}
\end{gathered}
$$

where $\varphi_{0}$ is the interfacial potential at an electrolyte solution/gate insulator interface, $\mathrm{pH}_{\mathrm{pzc}}$ is the point of zero charge, $q$ is the elementary charge, $N_{\mathrm{S}}$ is the site density of hydroxyl groups at the oxide membrane, $K_{a}$ is the equilibrium constant between hydrogen ions and hydroxyl groups, $k$ is the Boltzmann constant, $T$ is the absolute temperature, and $C_{\mathrm{EDL}}$ is the capacitance of the electric double layer. ${ }^{21}$ The $\mathrm{Ta}_{2} \mathrm{O}_{5}$-gate ISFET shows higher $\mathrm{pH}$ sensitivity near the ideal sensitivity owing to the higher density of hydroxy groups at the $\mathrm{Ta}_{2} \mathrm{O}_{5}$ surface $\left(\mathrm{ca} .10^{15} / \mathrm{cm}^{2}\right){ }^{38}$ which is sufficiently high for $\beta /(\beta+1)$ to be assumed as 1 . On the other hand, the BZ reaction is induced under a strongly acidic condition. This is why the change in $\mathrm{pH}$ during the $\mathrm{BZ}$ oscillation may have never been expected. However, the $\mathrm{pH}$ oscillation was induced upon adding malonic acid to the BZ presolution (malonic-acid-free) and was clearly detected using the single-gate ISFET sensor, as shown in Figure 1. The actual pH was estimated from the calibration curve ( $\Delta V_{\text {out }}$ with $\left.\Delta \mathrm{pH}\right)$ of the single-gate ISFET sensor used in this study (Figure S1). The average of the $\mathrm{pH}$ sensitivity was $55.2 \pm 2.1 \mathrm{mV} / \mathrm{pH}(\mathrm{n}=10)$ and then the $\mathrm{pH}$ of the BZ presolution was determined to be around 1.0 (Figure S1). In the BZ solution with the concentration of $\chi$, the peak-to-peak $\Delta V_{\text {out }}\left(\Delta V_{\text {out }}^{\text {peak }}\right)$ was approximately $43 \mathrm{mV}$, which corresponded to $\Delta \mathrm{pH} \approx 0.8$, and the period of the $\mathrm{pH}$ oscillation was approximately $67 \mathrm{~s}$ (Figure 1). Moreover, the peak-to-peak $\Delta \mathrm{pH}$ based on $\Delta V_{\text {out }}^{\text {peak }}$ and the oscillation period depended on the concentration of the BZ solution, as shown in Figure 2. The concentration ratio for each component in the $\mathrm{BZ}$ solution was constant throughout the oscillation reaction. At the lower concentration $(1 / 2 \times \chi)$, the $\mathrm{pH}$ oscillation was observed upon adding malonic 
acid, but it was gradually attenuated over time owing to the consumption of the substrates (Figure S2A). On the other hand, the $\mathrm{pH}$ oscillated more rapidly and lasted longer at the higher concentration $(2 \times \chi)$. This is because there were sufficient amounts of reactants in the BZ solution. Thus, a linear relationship between the peak-to-peak $\Delta \mathrm{pH}$ and the period of $\mathrm{pH}$ oscillation was found, depending on the concentration of the BZ solution. That is, the $\mathrm{pH}$ oscillation induced by the BZ reaction was clearly demonstrated even under the strongly acidic condition because the ISFET sensor can selectively detect the change in $\mathrm{pH}$. However, we should investigate further to more convincingly show how the $\mathrm{pH}$ oscillation is involved in other reactions such as a cyclic redox reaction involving metallic catalysts.

The redox reaction of the ruthenium ion complex on the Pt electrode is

$$
\mathrm{Ru}(\mathrm{bpy}) 3^{3+}+\mathrm{e}^{-} \rightleftarrows \mathrm{Ru}(\text { bpy }) 3^{2+} \text {. }
$$

From the Nernst equation, the electrode potential $E$, which is induced between the Pt electrode and the reference electrode, is expressed by

$$
E=E_{0}+2.303 \frac{R T}{F} \log \frac{\left[\mathrm{Ru}(\mathrm{bpy})_{3}{ }^{3+}\right]}{\left[\mathrm{Ru}(\mathrm{bpy})_{3}{ }^{2+}\right]} \text {, }
$$

where $E_{0}$ is the standard electrode potential, $R$ is the gas constant, $T$ is the absolute temperature, and $F$ is the Faraday constant. Therefore, the potential based on the BZ reaction is shown by

$$
E-E_{0} \propto \log \frac{\left[\mathrm{Ru}(\mathrm{bpy})_{3}{ }^{3+}\right]}{\left[\mathrm{Ru}(\mathrm{bpy})_{3}{ }^{2+}\right]} .
$$

Indeed, the redox potential of the ruthenium ion complex oscillated with a period consistent with that of $\left[\mathrm{H}^{+}\right]$and $\left[\mathrm{Br}^{-}\right]$oscillations, as shown in Figure 3. $\left[\mathrm{Br}^{-}\right]$was simultaneously measured using a bromide-selective electrode (8005-10C, HORIBA). The redox reaction of the ruthenium ion complex was also confirmed by the change in the color of the BZ solution (Figure S3). That is, the G component in the RGB color analysis was oscillated, similarly to 
the redox potential oscillation (orange $\mathrm{Ru}(\mathrm{bpy})_{3}{ }^{2+}$ from/to light-green $\mathrm{Ru}(\mathrm{bpy})_{3}{ }^{3+}$ ). Considering the Field, Koros, and Noyes (FKN) mechanism, ${ }^{9}$ the $\mathrm{BZ}$ reaction takes place via three processes (A, B, and C), as shown in Table S2. The inhibitor $\mathrm{Br}^{-}$is removed in Process A; the activator species $\mathrm{HBrO}_{2}$ is produced autocatalytically and the catalyst is oxidized in Process $\mathrm{B}$; and the inhibitor $\mathrm{Br}^{-}$is reformed upon reduction of the catalyst in Process $\mathrm{C}$. From Figure 3, the timing of peak potentials involved in $\left[\mathrm{Ru}(\mathrm{bpy})_{3}{ }^{3+/ 2+}\right]$ and $\left[\mathrm{Br}^{-}\right]$were in reasonable accordance with the three processes. On the other hand, the increase and decrease in $\left[\mathrm{H}^{+}\right]$did not appear to follow three processes, showing a slight deviation of peak potentials (i.e., the phase shift) from those involved in $\left[\mathrm{Ru}(\mathrm{bpy})_{3}{ }^{3+/ 2+}\right]$ and $\left[\mathrm{Br}^{-}\right]$(dotted circle in Figure 3), although each period was consistent. Considering each reaction in the three processes and the sequence (e.g., Processes $A \rightarrow B \rightarrow C$ ) shown in Table S2, the sequence for the change in $\left[\mathrm{H}^{+}\right]$also seemed to shift one by one (i.e., Processes $\mathrm{B} \rightarrow \mathrm{C} \rightarrow \mathrm{A}$ ). That is, the $\mathrm{pH}$ oscillation could not be simply explained from the reaction equations shown for the FKN mechanism. In the $\mathrm{pH}$ oscillation obtained in the FET measurements, malonic acid was added to the $\mathrm{BZ}$ presolution ( $\mathrm{pH}$ 1.0). This indicates that malonic acid with higher $\mathrm{pH}$ may have undergone $\mathrm{H}^{+}$, which resulted in the decrease in $\left[\mathrm{H}^{+}\right]$in the $\mathrm{BZ}$ solution with lower $\mathrm{pH}$, showing its equilibrium reaction $\left[\mathrm{CH}_{2}(\mathrm{COOH})_{2} \rightleftarrows \mathrm{CH}_{2}(\mathrm{COOH})\left(\mathrm{COO}^{-}\right)+\mathrm{H}^{+} \rightleftarrows \mathrm{CH}_{2}\left(\mathrm{COO}^{-}\right)_{2}+\right.$ $2 \mathrm{H}^{+}, \mathrm{pK}_{\mathrm{a}} 2.83$ and 5.69]. In fact, $\Delta V_{\text {out }}\left(\left[\mathrm{H}^{+}\right]\right)$gradually decreased after the addition of malonic acid, which resulted in pHs 2-3 with the generation of $\mathrm{BrCH}_{2}(\mathrm{COOH})_{2}$ before $\Delta V_{\text {out }}$ $\left(\left[\mathrm{H}^{+}\right]\right)$first increased (the $\mathrm{pH}$ oscillation was observed) (Figures 1 and S2). Therefore, the equilibrium reaction of malonic acid may be considered for the $\mathrm{pH}$ oscillation induced by the $\mathrm{BZ}$ reaction, on the basis of our consideration. However, the driving force for the increase in $\left[\mathrm{H}^{+}\right]$cannot be explained from this point. Basically, ruthenium ion complexes showed trivalent $\mathrm{Ru}(\mathrm{bpy})_{3}{ }^{3+}$ (oxidation state) in the $\mathrm{BZ}$ presolution ( $\mathrm{pH} 1.0$ ), which was confirmed from its color (light-green), as shown in Figure S1. That is, the increase in $\left[\mathrm{H}^{+}\right]$appeared to be related 
to the oxidation state of ruthenium ion complexes. In this case, the ruthenium ion complexbromomalonic acid subsystem, the reaction steps of which are given below (reaction equations 6 and 7), may be required for the increase in $\left[\mathrm{H}^{+}\right]$during the $\mathrm{pH}$ oscillation, considering the results of simulation reported in a previous paper. ${ }^{8}$ Note that the oxidation reactions of ruthenium ion complexes, that is, the generation of $\mathrm{Ru}(\mathrm{bpy})_{3}{ }^{3+}$, should have simultaneously proceeded in Process B at this time in this study.

$$
\begin{gathered}
\mathrm{Ru}(\mathrm{bpy})_{3}{ }^{3+}+\mathrm{BrCH}_{2}(\mathrm{COOH})_{2} \rightleftarrows\left[\mathrm{Ru}(\mathrm{bpy})_{3}(\mathrm{III}) \mathrm{BrCH}_{2}(\mathrm{COOH})_{2}\right]^{+}+2 \mathrm{H}^{+} \\
\mathrm{Ru}(\mathrm{bpy})_{3}{ }^{3+}+\left[\mathrm{Ru}(\mathrm{bpy})_{3}(\mathrm{III}) \mathrm{BrCH}_{2}(\mathrm{COOH})_{2}\right]^{+} \\
\rightleftarrows \text { tartraric acid }+2 \mathrm{Ru}(\mathrm{bpy})_{3}{ }^{2+}+\mathrm{Br}^{-}+\mathrm{H}^{+}
\end{gathered}
$$

This assumption also provides the generation of $\mathrm{Ru}(\mathrm{bpy})_{3}{ }^{2+}$ as well as $\mathrm{H}^{+}$, which may explain the slight deviation of peak potentials in $\left[\mathrm{H}^{+}\right]$(dotted circle in Figure 3). From the above considerations, malonic acid with higher $\mathrm{pH}$ was added to the $\mathrm{BZ}$ presolution with lower $\mathrm{pH}$ and then the dissociated malonic acid underwent $\mathrm{H}^{+}$on the basis of its equilibrium reaction, resulting in the decrease in $\left[\mathrm{H}^{+}\right]$(Process X). Subsequently, undissociated malonic acid reacted with $\mathrm{Br}_{2}$, which generated $\mathrm{BrCH}_{2}(\mathrm{COOH})_{2}$, in accordance with the usual process. $\mathrm{BrCH}_{2}(\mathrm{COOH})_{2}$ was incorporated in the ruthenium ion complex-bromomalonic acid subsystem, resulting in $\left[\mathrm{H}^{+}\right]$increase (Process $\mathrm{Y}$ ). After the increase in $\left[\mathrm{H}^{+}\right]$based on this assumption, malonic acid spontaneously maintained its equilibrium reaction to reduce $\left[\mathrm{H}^{+}\right]$ again (Process $\mathrm{X}$ ). This is why Processes $\mathrm{X}$ and $\mathrm{Y}$ may have periodically occurred in turn; that is, the $\mathrm{pH}$ oscillation may have been electrically observed using the ISFET sensor. However, the peak $\mathrm{pH}$ and the period of $\mathrm{pH}$ oscillation simulated in a previous work gradually increased over time, ${ }^{8}$ whereas in this study they were almost constant (Figures $\mathbf{1}$ and S2). Therefore, such a $\mathrm{pH}$ oscillation induced by the $\mathrm{BZ}$ reaction should be further simulated in the future to elucidate the reaction mechanism. Although there have already been numerous studies in which the reaction rates of catalysts and intermediates were analyzed, changes in $\left[\mathrm{H}^{+}\right]$were not 
considered.

$\mathrm{pH}$ oscillation imaging with arrayed-gate ISFET sensor

The large-scale and high-density ISFET sensor (arrayed-gate ISFET sensor) chip, which was developed on the basis of CMOS integrated circuit technologies, ${ }^{34}$ enabled the twodimensional imaging of $\mathrm{pH}$ oscillation induced by the $\mathrm{BZ}$ reaction. Figure $\mathbf{S 4}$ shows $\Delta V_{\text {out }}$ with the change in $\mathrm{pH}$ from 4.01 to 9.18 , detected using the arrayed-gate ISFET sensor. The data shown in Figure S4A were obtained from three ISFETs, which were randomly chosen from among the $256 \times 256$ ISFETs. $\Delta V_{\text {out }}$ changed immediately after changing the $\mathrm{pH}$ buffer, indicating the good responsivity to the change in $\mathrm{pH} . \Delta V_{\text {out }}$ shifted in the negative direction when $\mathrm{pH}$ was changed from 1.68 to 10.01 , and then $\Delta V_{\text {out }}$ returned to the original value in a stepwise manner for the repeated $\mathrm{pH}$ measurements, similarly to the single-gate ISFET sensor. This result demonstrates that the $\mathrm{Ta}_{2} \mathrm{O}_{5}$ membrane as the gate insulator of the arrayed-gate ISFET sensor developed in this study remained electrochemically stable when immersed in solutions of various $\mathrm{pHs}$ and that each ISFET operated stably. Considering the data shown in Figure S4A, a linear plot of $\Delta V_{\text {out }} \mathrm{vs} \mathrm{pH}$ was obtained from the $256 \times 256$ arrayed ISFETs, $0.5 \%$ of which were excluded from the evaluation owing to electrical failures, as shown in Figure S4B. This calibration curve indicated a $\mathrm{pH}$ sensitivity of $55.6 \mathrm{mV} / \mathrm{pH}$ near the Nernstian response. Thus, the electrical responsivity of the arrayed-gate ISFET sensor to changes in $\mathrm{pH}$ was in good agreement with that of the single-gate ISFET sensor shown in Figure S1. In addition, the arrayed-gate ISFET sensor measures two-dimensionally the change in $\mathrm{pH}$, which is in contrast to the single-gate ISFET that measures the change in $\mathrm{pH}$ at a local point, and can be used as a $\mathrm{pH}$ image sensor.

Using the arrayed-gate ISFET sensor, we monitored the $\mathrm{pH}$ oscillation induced by the BZ reaction in real time, as shown in Figures 4 and S5. From $\Delta V_{\text {out }}$ for the arrayed-gate ISFET sensor, the $\mathrm{pH}\left(-\log \left[\mathrm{H}^{+}\right]\right)$oscillation was clearly observed upon adding malonic acid to the BZ 
presolution at the concentration of $\chi$ (Figure 4), similarly to $\Delta V_{\text {out }}$ monitored by the single-gate ISFET (Figure 1). In addition, the arrayed-gate ISFET sensor, as the $\mathrm{pH}$ image sensor, visually demonstrated the $\mathrm{pH}$ oscillation induced by the $\mathrm{BZ}$ reaction in real time via the change in the color, which corresponded to $\Delta V_{\text {out }}$, as shown in the movie (Figure S5). The oscillation period was approximately $30-40 \mathrm{~s}$, whereas $\Delta V_{\text {out }}^{\text {peak }}$ for the arrayed-gate ISFET sensor was approximately $10 \mathrm{mV}(\Delta \mathrm{pH} \approx 0.2)$ smaller than that for the single-gate ISFET, despite the similar trend of $\mathrm{pH}$ sensitivity. This may be due to the fact that the volume of the measurement solution in the arrayed-gate ISFET sensor was $1 \mathrm{~mL}$ smaller than that in the single-gate ISFET $(10 \mathrm{~mL})$; moreover, the effect of stirring of the BZ solution was different. Thus, the chemical self-oscillation was imaged in real time on the basis of the change in $\mathrm{pH}$ using the CMOS integrated circuit device. In addition, to observe the patterns similar to a series of expanding concentric rings of the BZ reaction observed in petri dishes (target pattern), ${ }^{39}$ several arrayedgate ISFET sensor chips may be arranged on a wider area in the future.

\section{Chemoelectrical self-oscillation of polymer brush with single-gate ISFET sensor}

As shown in the above sections, the solution-gated ISFET sensor can directly detect the $\mathrm{pH}$ oscillation induced by the $\mathrm{BZ}$ reaction on the $\mathrm{Ta}_{2} \mathrm{O}_{5}$ gate insulator with hydroxy groups, which show the equilibrium reaction with hydrogen ions. On the other hand, such a sensing surface is chemically modified and functionalized to detect target samples by ion-sensitive membranes and biomolecular recognition sites such as DNA probes and enzymes. ${ }^{22,40}$ The chemical modification on the $\mathrm{Ta}_{2} \mathrm{O}_{5}$ gate insulator contributes to the specific and selective detection of target ions and biomolecules at the expense of losing the original $\mathrm{pH}$ sensitivity owing to the blocking of hydroxy groups. In particular, the thermoresponsive poly( $N$-isopropylacrylamide) (PNIPAAm) brushes grafted on the $\mathrm{Ta}_{2} \mathrm{O}_{5}$ gate insulator were evaluated as a bioelectrical interface for biosensing on the basis of the electrical property of the ISFET sensor. In this case, the difference between the capacitances of the PNIPAAm brushes at the swelling state and the 
deswelling state was found in previous studies. ${ }^{37,41}$ Moreover, the PNIPAAm gel copolymerized with ruthenium complexes (one of the catalysts) shows the self-oscillating behavior on the basis of the BZ reaction with the redox reaction of complexes. ${ }^{5,18}$ That is, the self-oscillating behavior based on the $\mathrm{BZ}$ reaction can also be observed as a change in the capacitance of the PNIPAAm brush with $\mathrm{Ru}(\mathrm{bpy})_{3}{ }^{3+/ 2+}$ grafted on the $\mathrm{Ta}_{2} \mathrm{O}_{5}$ gate insulator, using the ISFET sensor. The self-oscillating polymer [designed to be a random copolymer containing NIPAAm, Ru(bpy) $)_{3}$, and NAPMAm as binding sites of $\left.\mathrm{Ru}(\mathrm{bpy})_{3}\right]$, that is, the poly(NIPAAm- $r$-NAPMAm- $r$-Ru(bpy) $)_{3}$ NAPMAm) brush, was successfully grafted on the $\mathrm{Ta}_{2} \mathrm{O}_{5}$ gate insulator of the ISFET sensor by SI-ARGET ATRP, followed by the conjugation of $\mathrm{Ru}(\text { bpy) })_{3}$-NHS ester (Scheme 1). After cleaning the $\mathrm{Ta}_{2} \mathrm{O}_{5}$ gate surface, ATRP initiators were tethered at the surface with hydroxy groups by silane coupling. Then, NIPAAm and NAPMAm monomers were copolymerized by grafting from the surface with the initiators for $20 \mathrm{~h}$ to control the thickness of poly(NIPAAm- $r$-NAPMAm) in the aqueous solution with the mixture of reagents for ARGET ATRP. After the ARGET ATRP reaction, Ru(bpy) ${ }_{3}$-NHS ester was covalently reacted with amino groups of the poly(NIPAAm-r-NAPMAm) brush grafted on the $\mathrm{Ta}_{2} \mathrm{O}_{5}$ gate insulator. The thickness was measured to be approximately $20 \mathrm{~nm}$ in atmosphere by AFM (Figure S6). Using the prepared device, we electrically monitored the self-oscillation of the polymer brush, as shown in Figure 5. In the measurement, ruthenium ion complexes and malonic acid were not included in the $\mathrm{BZ}$ presolution at the concentration of $\chi$, and then malonic acid only was added to the poly(NIPAAm- $r$-NAPMAm- $r$-Ru(bpy $)_{3}$ NAPMAm) brushgrafted $\mathrm{Ta}_{2} \mathrm{O}_{5}$ gate surface. In particular, the glass substrate grafted with the same polymer brush was used to cover over the modified $\mathrm{Ta}_{2} \mathrm{O}_{5}$ gate surface to prevent the $\mathrm{BZ}$ components such as $\mathrm{Br}^{-}$from diffusing away from the active surface, that is, to maintain the $\mathrm{BZ}$ reaction at the surface (Figure S7). In fact, the poly(NIPAAm-r-NAPMAm-r-Ru(bpy) 3 NAPMAm) brush-grafted $\mathrm{Ta}_{2} \mathrm{O}_{5}$ gate ISFET demonstrated electrical self-oscillation, as detected on the 
basis of the swelling-deswelling behavior of the polymer brush. On the other hand, the poly(NIPAAm- $r$-NAPMAm) without $\mathrm{Ru}(\mathrm{bpy})_{3}$ brush-grafted $\mathrm{Ta}_{2} \mathrm{O}_{5}$ gate ISFET (control sensor) showed no electrical responses, although the signals of both sensors gradually and slightly decreased owing to the change in $\mathrm{pH}$ upon the addition of malonic acid, as shown in Figure 5A. Moreover, the difference between the signals of the two sensors $\left(\Delta V_{\text {out }}^{\text {diff }}\right)$ clearly showed the self-oscillation with an amplitude of approximately $3 \mathrm{mV}$ and a period of $40 \mathrm{~s}$ (Figure 5B). This self-oscillation signal was not caused by the change in $\mathrm{pH}$, judging from the electrical behavior of the control sensor. Therefore, the electrical self-oscillation of the poly(NIPAAm- $r$-NAPMAm- $r$-Ru(bpy) ${ }_{3}$ NAPMAm) brush-grafted $\mathrm{Ta}_{2} \mathrm{O}_{5}$ gate ISFET should have resulted from the change in the capacitance of the polymer brush attributable to its swelling and deswelling behavior, judging from the results reported in previous papers. ${ }^{37,41}$ From the view point of ionic charges, however, the modified ISFET sensor may have detected simultaneously the change in the charges of ruthenium ion complexes owing to the redox reaction $\left(\mathrm{Ru}(\mathrm{bpy})_{3}{ }^{2+} \rightleftarrows \mathrm{Ru}(\mathrm{bpy})_{3}{ }^{3+}\right)$ on the $\mathrm{Ta}_{2} \mathrm{O}_{5}$ gate surface, similarly to the principle of $\mathrm{pH}$ sensing (see sect. 3.1). In this case, the effect of these charges on $\Delta V_{\text {out }}$ would have depended on the density of ruthenium ion complexes in the polymer brush grafted on the $\mathrm{Ta}_{2} \mathrm{O}_{5}$ gate surface. Also, the increase in the density of positive charges based on the oxidation reaction should have induced the increase in $\Delta V_{\text {out, }}$ in accordance with the source-follower circuit employed in this study. ${ }^{41}$ On the other hand, the effect of the change in the capacitance of the polymer brush on $\Delta V_{\text {out }}$ should be additionally considered for the self-oscillating polymer (i.e., swelling $\rightleftarrows$ deswelling). In previous works, the thermoresponsive PNIPAAm-brush-grafted $\mathrm{Ta}_{2} \mathrm{O}_{5}$ gate ISFET clearly showed $\Delta V_{\text {out }}$ for the change in the temperature, which induced the swelling-deswelling behavior of the PNIPAAm brush past the lower critical solution temperature (LCST), resulting in the change in the capacitance of the PNIPAAm brush. ${ }^{37,41}$ Considering the discussion in previous works, the capacitance of the polymer brush in the 
swelling state would have been larger than that in the deswelling state owing to the hydration of the polymer brush, resulting in the increase in $\Delta V_{\text {out. }}$ That is, $\Delta V_{\text {out }}$ of the poly(NIPAAm- $r$ NAPMAm- $r$-Ru(bpy) ${ }_{3}$ NAPMAm)-brush-grafted $\mathrm{Ta}_{2} \mathrm{O}_{5}$ gate ISFET should have increased on the basis of the phase transition caused by the oxidation of $\mathrm{Ru}(\mathrm{bpy})_{3}{ }^{2+}$ to $\mathrm{Ru}(\mathrm{bpy})_{3}{ }^{3+}$ (i.e., swelling). This indicates that the positive shift in $\Delta V_{\text {out }}$ for the self-oscillating polymer brush may have been synergistically induced by the increases in the density of ionic charges of ruthenium ion complexes (bivalent to trivalent ions) and the capacitance of the polymer brush with swelling, which were primarily induced by the oxidation reaction. Moreover, ruthenium ion complexes were covalently introduced into the polymer brush, which then enhanced the ionization of the polymer brush; therefore, the transition between hydration and dehydration appeared to smoothly occur at the poly(NIPAAm-r-NAPMAm- $r$-Ru(bpy) ${ }_{3}$ NAPMAm)-brushgrafted $\mathrm{Ta}_{2} \mathrm{O}_{5}$ gate surface (Figure 5). The amount of output signals (i.e., the amplitude) and periods would have been mainly derived from the length and density of the polymer brush chain and the concentration of BZ solution. From the slope of $\Delta V_{\text {out }}^{\text {diff }}$ for its increase or decrease, the reaction rate for the oxidation appeared to be higher than that for reduction. ${ }^{5}$ This indicates that the swelling behavior of the poly(NIPAAm- $r$-NAPMAm- $r$-Ru(bpy) ${ }_{3}$ NAPMAm) brush would have occurred more smoothly than its deswelling behavior at the $\mathrm{Ta}_{2} \mathrm{O}_{5}$ gate surface. Thus, the chemical self-oscillation behavior that resulted in the structural change of the polymer brush with the swelling-deswelling transition was successfully monitored as the electrical self-oscillating behavior using the ISFET sensor. This suggests that such chemical oscillations can generate electrical energies for future self-oscillating sensors and actuators.

\section{Conclusion}

In this study, we demonstrated the electrical monitoring of self-oscillation behaviors at the chemoelectrical interface based on the BZ reaction between the electrolyte solution and the 
$\mathrm{Ta}_{2} \mathrm{O}_{5}$ gate insulator of the ISFET sensor. First, the $\mathrm{pH}$ oscillation induced by the $\mathrm{BZ}$ reaction was electrically monitored using the nonmodified single-gate and arrayed-gate ISFET sensors. This is because the ISFET sensors had the superior ability to detect ionic charges; otherwise, the oxide gate surface with hydroxy groups in the solution showed the equilibrium reaction with hydrogen ions with positive charges, depending on the $\mathrm{pH}$ at such a chemoelectrical interface. In particular, the arrayed-gate ISFET sensor provided images of the $\mathrm{pH}$ oscillation owing to the large-scale and high-density format. To clarify the mechanism of the BZ reaction with $\mathrm{pH}$ oscillation, the ruthenium ion complex-bromomalonic acid subsystem may be added to it, considering the simulation of the $\mathrm{pH}$ oscillation shown in a previous paper. ${ }^{8}$ In addition, the equilibrium reaction of malonic acid should be considered to elucidate the BZ reaction mechanism including the $\mathrm{pH}$ oscillation owing to the relatively large difference between the $\mathrm{pH}$ of $\mathrm{BZ}$ presolution $(\approx 1)$ and the $\mathrm{pKa}$ of the malonic acid $(\approx 3)$ added. Second, the selfoscillating polymer brush, poly(NIPAAm- $r$-NAPMAm- $r$-Ru(bpy) 3 NAPMAm), grafted on the $\mathrm{Ta}_{2} \mathrm{O}_{5}$ gate insulator by SI-ARGET ATRP, clearly exhibited the periodical electrical response of the ISFET sensor. This self-oscillation behavior was mainly based on the change in the capacitance of the polymer brush derived from its swelling-deswelling behavior based on the $\mathrm{BZ}$ reaction on the surface of $\mathrm{Ta}_{2} \mathrm{O}_{5}$ gate insulator, that is, at the chemoelectrical interface, although the effect of ionic charges may be considered as well. From the above, the elucidation of the electrical self-oscillation behaviors based on the BZ reaction using the ISFET sensor provides a solution to the problems of nonequilibrium chemistry. Moreover, such chemical oscillations may generate electrical energies for future self-oscillating sensors and actuators.

\section{Methods}

\section{Chemicals}

The following chemicals and materials were used in this study. $N$-isopropylacrylamide 
(NIPAAm) was provided by KJ Chemicals (Tokyo, Japan) and purified by recrystallization in toluene/hexane. $\quad$ Tris[2-(N,N-dimetylamino)ethyl]amine $\quad\left(\mathrm{Me}_{6} \mathrm{TREN}\right), \quad N-3-$ (aminopropyl)methacrylamide (NAPMAm) hydrocholoride, Ru(bpy) 3 - $N$-hydroxysuccinimide (NHS) ester, methyl 2-chloropropionate (MCP), and L-ascorbic acid were purchased from Tokyo Chemical Industries (Tokyo, Japan). Nitric acid $\left(\mathrm{HNO}_{3}\right)$, sodium bromate $\left(\mathrm{NaBrO}_{3}\right)$, malonic acid $\left[\mathrm{CH}_{2}(\mathrm{COOH})_{2}\right]$, tris(bipyridine)ruthenium (II) chloride $\left[\mathrm{Ru}(\mathrm{bpy})_{3}{ }^{2+} 2 \mathrm{Cl}^{-}\right]$, copper (I) chloride $(\mathrm{CuCl})$, [(chloromethyl)phenylethyl] trimethoxysilane (CMPETMS), triethylamine, $N, N$-dimethylformamide (DMF), dimethyl sulfoxide (DMSO, super dehydrated), toluene, dehydrated toluene, acetone, and methanol were purchased from Wako Pure Chemical Industries (Osaka, Japan).

\section{Devices}

We used two types of ISFET sensor for monitoring the $\mathrm{pH}$ oscillation induced by the BZ reaction in this study. One was the single-gate ISFET sensor, which was composed of a siliconbased n-channel depletion-mode FET with a $\mathrm{Ta}_{2} \mathrm{O}_{5} / \mathrm{SiO}_{2}(100 \mathrm{~nm} / 50 \mathrm{~nm})$ layer as the gate insulator with a width $(W)$ of $340 \mu \mathrm{m}$ and a length $(L)$ of $10 \mu \mathrm{m}$, respectively (ISFETCOM Co., Ltd.). The other type was the arrayed-gate ISFET sensor, which was composed of $256 \times 256$ pixels with a $\mathrm{Ta}_{2} \mathrm{O}_{5}(300 \mathrm{~nm})$ layer as the gate insulator. Also, the sensing area of one pixel was $1.42 \times 1.42 \mu \mathrm{m}^{2}$ and the pixel pitch was $2 \times 2 \mu \mathrm{m}^{2}$. Other sensor performance parameters are shown in Table $\mathbf{S 1}$ and described in a previous paper. ${ }^{34}$

The extended-gate ISFET sensor was used for monitoring a self-oscillation behavior of a polymer brush grafted to the $\mathrm{Ta}_{2} \mathrm{O}_{5}$ gate surface. In this case, $\mathrm{Ta}_{2} \mathrm{O}_{5}$ film $(100 \mathrm{~nm})$ with the surface area of $12 \times 12 \mathrm{~mm}^{2}$ was sputtered on a $\mathrm{Au}(100 \mathrm{~nm}) / \mathrm{Cr}(20 \mathrm{~nm})$ electrode, which was connected to the gate of a silicon-based n-channel junction-type FET (K246-Y9A, Toshiba), as an extended-gate electrode, considering ease of surface treatments. ${ }^{42,43}$

The $\mathrm{Ta}_{2} \mathrm{O}_{5}$ thin film was used as the passivation layer to prevent the leakage of currents as 
well as the $\mathrm{pH}$-responsive layer in an electrolyte solution. A polycarbonate ring of 10 or $20 \mathrm{~mm}$ inner diameter was encapsulated to pour measurement solutions onto the $\mathrm{Ta}_{2} \mathrm{O}_{5}$ gate surface $(0.5$ or $1 \mathrm{~mL})$ as a measurement well. Also, the single-gate ISFET sensor was immersed in a 5 $\mathrm{mL}$ measurement solution in a beaker for monitoring the $\mathrm{pH}$ oscillation.

\section{Electrical measurement of $\mathrm{pH}$ oscillation induced by $\mathrm{BZ}$ reaction using ISFET sensors}

To confirm the fundamental electrical properties of the single-gate ISFET sensor, its gate voltage $\left(V_{\mathrm{G}}\right)$-drain current $\left(I_{\mathrm{D}}\right)$ electrical characteristics were measured using a semiconductor parameter analyzer (B1500A, Agilent). A change in $V_{\mathrm{G}}$ in $V_{\mathrm{G}}-I_{\mathrm{D}}$ electrical characteristics was estimated as a threshold voltage $\left(V_{\mathrm{T}}\right)$ shift, which was evaluated at a constant $I_{\mathrm{D}}$ of $700 \mu \mathrm{A}$ and a constant drain voltage $\left(V_{\mathrm{D}}\right)$ of $2 \mathrm{~V}$. $\mathrm{A} \mathrm{Ag} / \mathrm{AgCl}$ reference electrode with a $\mathrm{KCl}$ solution was connected to the measurement solution through a salt bridge. As the $\mathrm{pH}$ measurement solution, standard buffer solutions with pHs of 1.68, 4.01, 6.86, 9.18, and 10.01 (Wako Pure Chemical Industries, Ltd.) were prepared. The time course of the change in surface potential at the gate surface $\left(\Delta V_{\text {out }}\right)$ was monitored using a source follower circuit, ${ }^{35}$ with which the potential change at the interface between an aqueous solution and a gate insulator can be read out directly at a constant $I_{\mathrm{D}}$ (RadianceWare Inc.). In this study, $V_{\mathrm{D}}$ and $I_{\mathrm{D}}$ were set to $1 \mathrm{~V}$ and $700 \mu \mathrm{A}$, respectively. On the other hand, the $\mathrm{pH}$ responsivity of the arrayed-gate ISFET sensor was monitored from $\mathrm{pH} 1.68$ to $\mathrm{pH} 10.01$ at the frame speed of $3.4 \mathrm{fps}$ in this study, in accordance with the measurement setup shown in a previous work. ${ }^{34}$ The measurement data $\left(\Delta V_{\text {out }}\right)$ was automatically transformed into output images using a measuring software installed on a PC. For both ISFET sensors, $\Delta V_{\text {out }}$ was calibrated on the basis of the change in $\mathrm{pH}$ to analyze the pH sensitivity.

The BZ solution was composed of $1 \mathrm{M} \mathrm{HNO}_{3}, 1 \mathrm{M} \mathrm{NaBrO}_{3}, 1 \mathrm{M} \mathrm{CH}_{2}(\mathrm{COOH})_{2}$, and $1 \mathrm{mM}$ $\mathrm{Ru}(\mathrm{bpy}){ }_{3}{ }^{2+} 2 \mathrm{Cl}^{-}$in deionized water, the concentrations of which are expressed as $\chi$. That is, the BZ solution with $1 / 2 \times \chi$ was adjusted to $0.5 \mathrm{M} \mathrm{HNO}_{3}, 0.5 \mathrm{M} \mathrm{NaBrO}_{3}, 0.5 \mathrm{M} \mathrm{CH}_{2}(\mathrm{COOH})_{2}$, 
and $0.5 \mathrm{mM} \mathrm{Ru}(\mathrm{bpy})_{3}{ }^{2+} 2 \mathrm{Cl}^{-}$for each component in deionized water, for example. In the electrical measurement, malonic acid was added to the BZ presolution without malonic acid and the BZ solutions were stirred under batch conditions. The total volume of the BZ solution was controlled to be $0.5,1$, or $5 \mathrm{~mL}$, depending on the size of measurement wells. The $\mathrm{pH}$ oscillation induced by the BZ reaction was observed on the basis of $\Delta V_{\text {out }}$ of both ISFET sensors without chemical modifications.

\section{Surface modification of polymer brush on $\mathrm{Ta}_{2} \mathrm{O}_{5}$ gate surface}

Chemical modification of atom transfer radical polymerization (ATRP) initiator on $\mathrm{Ta}_{2} \mathrm{O}_{5}$ gate surface

The self-oscillation behavior of a polymer brush grafted to the $\mathrm{Ta}_{2} \mathrm{O}_{5}$ gate surface was examined using the extended- $\mathrm{Ta}_{2} \mathrm{O}_{5}$-gate ISFET sensor, similarly to the single-gate ISFET sensor. The ATRP initiator (CMPETMS) was chemically modified on the $\mathrm{Ta}_{2} \mathrm{O}_{5}$ gate surface by the silane coupling reaction. The $\mathrm{Ta}_{2} \mathrm{O}_{5}$ gate surface was cleaned by oxygen plasma irradiation, followed by washing with ethanol and deionized water. The cleaned $\mathrm{Ta}_{2} \mathrm{O}_{5}$ gate substrate was placed into a separable flask, in which the relative humidity was $60 \%$, for $2 \mathrm{~h}$. Toluene solution containing CMPETMS (1.2 v/v\%) was poured into the separable flask, and the solution was stirred for $20 \mathrm{~h}$ at $25^{\circ} \mathrm{C}$. The $\mathrm{Ta}_{2} \mathrm{O}_{5}$ gate surface with the ATRP initiator was washed with toluene and acetone and dried in a vacuum oven for $2 \mathrm{~h}$ at $110^{\circ} \mathrm{C}$.

Grafting of poly(NIPAAm-r-NAPMAm) brushes on $\mathrm{Ta}_{2} \mathrm{O}_{5}$ gate surface with initiator by surface-initiated activators regenerated by electron transfer (SI-ARGET) ATRP

The NIPAAm monomer $(5.65 \mathrm{~g}, 50 \mathrm{mmol})$ and NAPMAm hydrochloride $(0.895 \mathrm{~g}, 5 \mathrm{mmol})$ were dissolved in a mixed solvent of deionized water $(20 \mathrm{~mL})$ and DMF $(20 \mathrm{~mL}) \cdot \mathrm{CuCl}_{2}(13.5$ $\mathrm{mg}, 0.135 \mathrm{mmol})$ and $\mathrm{Me}_{6}$ TREN $(267.5 \mu \mathrm{L}, 1 \mathrm{mmol})$ were added to the solution. The solution was stirred for $15 \mathrm{~min}$ to obtain the $\mathrm{CuCl}_{2} / \mathrm{Me}_{6} \mathrm{TREN}$ catalyst system. The prepared ATRP solution was poured into a separable flask containing the ATRP-initiator-tethered $\mathrm{Ta}_{2} \mathrm{O}_{5}$ gate 
insulator. MCP $(21.5 \mu \mathrm{L}, 0.20 \mathrm{mmol})$, which acts as an unbound sacrificial ATRP initiator, was then added to the solution. Finally, L-ascorbic acid (176 $\mathrm{mg}, 1 \mathrm{mmol})$ was added to the solution, so that the ARGET ATRP reaction proceeded for $20 \mathrm{~h}$ at $25^{\circ} \mathrm{C}$ in the flask sealed with parafilm. After the ARGET ATRP reaction, the poly(NIPAAm- $r$-NAPMAm) brush-grafted $\mathrm{Ta}_{2} \mathrm{O}_{5}$ gate surface was thoroughly washed by ultrasonication in methanol and deionized water.

Addition of Ru(bpy) ${ }_{3}-\mathrm{NHS}$ ester to poly(NIPAAm-r-NAPMAm) brushes

$\mathrm{Ru}(\mathrm{bpy})_{3}$-NHS ester $(40.4 \mathrm{mg}, 0.20 \mathrm{mmol})$ and triethylamine $(16.8 \mu \mathrm{L}, 0.121 \mathrm{mM})$ were dissolved in DMSO $(200 \mu \mathrm{L}) .50 \mu \mathrm{L}$ of the mixed solution was poured onto the poly(NIPAAm$r$-NAPMAm)-brush-coated $\mathrm{Ta}_{2} \mathrm{O}_{5}$ gate surface. The reaction of $\mathrm{Ru}(\text { bpy })_{3}-\mathrm{NHS}$ esters with amines at NAPMAm was induced for $4 \mathrm{~h}$ at $25^{\circ} \mathrm{C}$, and then the poly(NIPAAm- $r$-NAPMAm$r$ - $\mathrm{Ru}(\text { bpy })_{3} \mathrm{NAPMAm}$ )-grafted $\mathrm{Ta}_{2} \mathrm{O}_{5}$ gate surface was thoroughly washed by ultrasonication in methanol and deionized water. The thickness was measured in atmosphere by atomic force microscopy (AFM).

\section{ASSOCIATED CONTENT}

\section{Supporting Information}

The Supporting Information is available free of charge on the ACS Publications website at DOI: $* * * *$.

Sensor performance parameters of arrayed-gate ISFET sensor (Table S1); Fundamental electrical properties of single-gate ISFET sensor (Figure S1); $\mathrm{pH}$ oscillation at $1 / 2 \times \chi$ and 2 $\times \chi$ using single-gate ISFET sensor (Figure S2); Change in color of BZ solution based on redox reaction of ruthenium bipyridine complex Ru(bpy) $3^{2+/ 3+}$ (Figure S3); Field, Koros, and Noyes (FKN) mechanism for BZ reaction (Table S2); Fundamental electrical properties of arrayedgate ISFET sensor (Figure S4); Visualized pH oscillation with arrayed-gate ISFET sensor (movie) (Figure S5); Thickness of poly(NIPAAm-r-NAPMAm) brush grafted on the $\mathrm{Ta}_{2} \mathrm{O}_{5}$ 
gate insulator (Figure S6); Measurement setup for self-oscillating polymer grafted on $\mathrm{Ta}_{2} \mathrm{O}_{5}$ gate surface (Figure S7).

\section{Author Information}

Corresponding author

*E-mail: sakata@biofet.t.u-tokyo.ac.jp

ORCID

Toshiya Sakata: 0000-0003-1246-5000

Notes

The authors declare no competing financial interest.

\section{Acknowledgments}

This study was partly supported by the Program on Open Innovation Platform with Enterprises, Research Institute and Academia (OPERA) of Japan Science and Technology (JST).

\section{Author contributions statement}

T. S. performed the experiments for the $\mathrm{pH}$ oscillation and wrote the original draft. S. N., Y. Y., K. H., and T. M. performed the experiments for the self-oscillating polymer. S. H. analyzed the self-oscillation behaviors. A. M. A., K. S., and R. Y. gave advice for the paper structure. T. S. and R. Y. corrected the original draft. All authors discussed the results and reviewed the final manuscript.

\section{Figure captions}

Figure 1. Change in interfacial potential $\left(\Delta V_{\text {out }}\right)$ for $\mathrm{BZ}$ reaction detected using single-gate 
ISFET sensor. Malonic acid was added to the $\mathrm{BZ}$ presolution without malonic acid ( $\mathrm{pH} 1.0$ ). $\Delta V_{\text {out }}$ was translated to $\mathrm{pH}$ in accordance with the $\mathrm{pH}$ sensitivity of the ISFET sensor (i.e., the Nernstian response) used in this study (Figure S1).

Figure 2. Peak-to-peak potential and $\mathrm{pH}$ (amplitude) for oscillation period based on Figures 1 and S2. The concentration $\chi$ of BZ solution was controlled to $1 / 2 \chi, \chi$, and $2 \chi$.

Figure 3. Self-oscillation behaviors of $\left[\mathrm{H}^{+}\right],\left[\mathrm{Ru}(\mathrm{bpy})^{3+} / \mathrm{Ru}(\mathrm{bpy})^{2+}\right]$, and $\left[\mathrm{Br}^{-}\right]$based on relative interfacial potential. The durations of Processes A, B, and C based on the FKN mechanism (Table S2) are delineated by the dotted lines (red). The dotted circle (black) shows the position of the peak $\left[\mathrm{H}^{+}\right]$.

Figure 4. $\mathrm{pH}$ oscillation behavior on arrayed-gate ISFET sensor. $\Delta V_{\text {out }}$ was output for $\mathrm{pH}$ analysis. The grey band around the line graph shows the standard errors for the $256 \times 256$ ISFETs except for $0.5 \%$ electrical failures.

Figure 5. Electrical monitoring of self-oscillating polymer brush grafted on $\mathrm{Ta}_{2} \mathrm{O}_{5}$ gate insulator using single-gate ISFET sensor. (A) Electrical signals for single-gate ISFET sensors with and without self-oscillating polymer brush. (B) Differential signal based on (A).

Scheme 1. Poly(NIPAAm- $r$-NAPMAm- $r$-Ru(bpy) $)_{3}$ NAPMAm) brush grafted on $\mathrm{Ta}_{2} \mathrm{O}_{5}$ gate surface by SI-ARGET ATRP.

\section{References}

(1) Belousov, B. P. Periodically acting reaction and its mechanism. Sb. Ref. Radiats. Med. 1958, Medgiz, Moscow 1959, 145-147.

(2) Zaikin, A. N.; Zhabotinsky, A. M. Concentration Wave Propagation in Two-dimensional Liquid-phase Self-oscillating System. Nature 1970, 225, 535-537.

(3) Schneider, F. Oscillations and Traveling Waves in Chemical Systems. Herausgegeben von R. J. Field und M. Burger. Angew. Chem. 1986, 98, 941-941. 
(4) Kalyanasundaram, K. Photophysics, Photochemistry and Solar Energy Conversion with Tris(bipyridyl)ruthenium(II) and Its Analogues. Coord. Chem. Rev. 1982, 46, 159-244.

(5) Yoshida, R. Self-Oscillating Gels Driven by the Belousov-Zhabotinsky Reaction as Novel Smart Materials. Adv. Mater. 2010, 22, 3463-3483.

(6) Noyes, R. M.; Field, R.; Koros, E. Oscillations in Chemical Systems. I. Detailed Mechanism in a System Showing Temporal Oscillations. J. Am. Chem. Soc. 1972, 94, $1394-1395$.

(7) Nemeth, B.; Busche, C.; Tsuda, S.; Cronin, L.; Cumming, D. R. S. Imaging the BelousovZhabotinsky Reaction in Real Time Using an Ion Sensitive Array. Chem. Commun. 2012, $48,5085-5087$.

(8) Frerichs, G. A.; Jones, J.; Huang, X.; Gebrekidan, M.; Burch, J.; Cheng, M. Y.; Chen, Y. Batch pH Oscillations in the Belousov-Zhabotinsky Reaction. J. Phys. Chem. A 2019, 123, $1303-1310$.

(9) Field, R. J.; Koros, E.; Noyes, R. M. Oscillations in Chemical Systems. II. Thorough Analysis of Temporal Oscillation in the Bromate-Cerium-Malonic Acid System. J. Am. Chem. Soc. 1972, 94, 8649-8664.

(10)Burger, M.; Koros, E. Conditions for the Onset of Chemical Oscillation. J. Phys. Chem. 1980, $84,496-500$.

(11)Field, R. J.; Försterling, H.-D. On the Oxybromtne Chemistry Rate Constants with Cerium Ions in the Field-Kórós-Noyes Mechanism of the Belousov-Zhabotinskii Reaction: The Equilibrium $\mathrm{HBrO}_{2}+\mathrm{BrO}_{3}{ }^{-}+\mathrm{H}^{+} \rightleftharpoons 2 \mathrm{BrO}_{2}{ }^{-}+\mathrm{H}_{2}$ O. J. Phys. Chem. 1986, 90, 5400-5407.

(12)Turanyi, T.; Gyorgyi, L.; Field, R. J. Analysis and Simplification of the GTF Model of the Belousov-Zhabotinsky Reaction. J. Phys. Chem. 1993, 97, 1931-1941.

(13) Sirimungkala, A.; Försterling, H.-D.; Dlask, V.; Field, R. J. Bromination Reactions Important in the Mechanism of the Belousov-Zhabotinsky System. J. Phys. Chem. A 1999, 
$103,1038-1043$.

(14)Blagojević, S. M.; Anić, S. R.; Čupić, Ž. D.; Pejić, N. D.; Kolar-Anić, L. Z. Malonic Acid Concentration as a Control Parameter in the Kinetic Analysis of the BelousovZhabotinsky Reaction under Batch Conditions. Phys. Chem. Chem. Phys. 2008, 10, 66586664.

(15)Prigogine, I.; Lefever, R. Symmetry Breaking Instabilities in Dissipative Systems. II. J. Chem. Phys. 1968, 48, 1695-1700.

(16)Prigogine, I.; Lefever, R.; Goldbeter, A.; Herschkowitz-Kaufman, M. Symmetry Breaking Instabilities in Biological Systems. Nature 1969, 223, 913-916.

(17) Yoshida, R.; Takahashi, T.; Yamaguchi, T.; Ichijo, H. Self-Oscillating Gel. J. Am. Chem. Soc. 1996, 118, 5134-5135.

(18) Yoshida, R.; Ueki, T. Evolution of Self-Oscillating Polymer Gels as Autonomous Polymer Systems. NPG Asia Mater. 2014, 6, e107.

(19) Yashin, V. V.; Kuksenok, O.; Dayal, P.; Balazs, A. C. Mechano-Chemical Oscillations and Waves in Reactive Gels. Rep. Prog. Phys. 2012, 75, 066601.

(20)Deb, D.; Kuksenok, O.; Dayal, P.; Balazs, A. C. Forming Self-Rotating Pinwheels from Assemblies of Oscillating Polymer Gels. Mater. Horiz. 2014, 1, 125-132.

(21)Bergveld, P. The Impact of MOSFET-Based Sensors. Sens. Actuators 1985, 8, 109-127.

(22) Sakata, T. Biologically Coupled Gate Field-Effect Transistors Meet in Vitro Diagnostics. ACS Omega 2019, 4, 11852-11862.

(23) Matsuo, T.; Wise, K. D. An Integrated Field-Effect Electrode for Biopotential Recording. IEEE Trans. Biomed. Eng. 1974, BME-21, 485- 487.

(24)Esashi, M.; Matsuo, T. Integrated Micro-Multi-Ion Sensor Using Field Effect of Semiconductor. IEEE Trans. Biomed. Eng. 1978, BME-25, 184-192.

(25)Sakata, T.; Nishimura, K.; Miyazawa, Y.; Saito, A.; Abe, H.; Kajisa, T. Ion Sensitive 
Transparent-Gate Transistor for Visible Cell Sensing. Anal. Chem. 2017, 89, 3901-3908.

(26) Sakata, T.; Nishitani, S.; Saito, A.; Fukasawa, Y. Solution-Gated Ultrathin Channel Indium

Tin Oxide-Based Field-Effect Transistor Fabricated by a One-Step Procedure that Enables High-Performance Ion Sensing and Biosensing. ACS Appl. Mater. Interfaces 2021, 13, 38569-38578.

(27)Nakazawa, H.; Ishida, M.; Sawada, K. Multimodal Bio-Image Sensor for Real-Time Proton and Fluorescence Imaging. Sens. Actuators, B: Chemical 2013, 180, 14-20.

(28)Nabovati, G.; Ghafar-Zadeh, E.; Sawan, M. A 64 Pixel ISFET-Based Biosensor for Extracellular pH Gradient Monitoring. 2015 IEEE Int. Symp. Circuits Syst. (ISCAS) 2015, $1762-1765$.

(29)Huang, X.; Yu, H.; Liu, X.; Jiang, Y.; Yan, M.; Wu, D. A Dual-Mode Large-Arrayed CMOS ISFET Sensor for Accurate and High-Throughput pH Sensing in Biomedical Diagnosis. IEEE Trans. Biomed. Eng. 2015, 62, 2224-2233.

(30)Duarte-Guevara, C.; Swaminathan, V.; Reddy Jr, B.; Wen, C.-H.; Huang, Y.-J.; Huang, J.C.; Liu, Y.-S.; Bashir, R. Characterization of a 1024 × 1024 DG-BioFET platform. Sens. Actuators, B: Chemical 2017, 250, 100-110.

(31)Kaisti, M.; Zhang, Q.; Levon, K. Compact Model and Design Considerations of an IonSensitive Floating Gate FET. Sens. Actuators, B: Chemical 2017, 241, 321-326.

(32)Cheah, B. C.; Macdonald, A. I.; Martin, C.; Streklas, A. J.; Campbell, G.; Al-Rawhani, M. A.; Nemeth, B.; Grant, J. P.; Barrett, M . P.; Cumming, D. R. S. An Integrated Circuit for Chip-Based Analysis of Enzyme Kinetics and Metabolite Quantification. IEEE Trans. Biomed. Circuits Syst. 2016, 10, 721-730.

(33)Jiang, Y.; Liu, X.; Dang, T. C.; Huang, X.; Feng, H.; Zhang, Q.; Yu, H. A High-Sensitivity Potentiometric 65-nm CMOS ISFET Sensor for Rapid E. coli Screening. IEEE Trans. Biomed. Circuits Syst. 2018, 12, 402-415. 
(34)Lee, Y.-N.; Araki, T.; Kimura, Y.; Dasai, F.; Iwata, T.; Takahashi, K.; Sawada, K. HighDensity 2- $\mu \mathrm{m}$-Pitch pH Image Sensor With High-Speed Operation up to $1933 \mathrm{fps}$. IEEE Trans. Biomed. Circuits Syst. 2019, 13, 352-363.

(35)Nishitani, S.; Sakata, T. Polymeric Nanofilter Biointerface for Potentiometric SmallBiomolecule Recognition. ACS Appl. Mater. Interfaces 2019, 11, 5561-5569.

(36) Sakata, T.; Nishitani, S.; Kajisa, T. Molecularly Imprinted Polymer-Based Bioelectrical Interface with Intrinsic Molecular Charges. RSC Advances 2020, 10, 16999-17013.

(37)Masuda, T.; Kajisa, T.; Akimoto, A. M.; Fujita, A.; Nagase, K.; Okano, T.; Sakata, T.; Yoshida, R. Dynamic Electrical Behaviour of Thermoresponsive Polymer in Well-Defined Poly(N-isopropylacrylamide)-Grafted Semiconductor Devices. RSC Advances 2017, 7, $34517-34521$.

(38)Akiyama, T.; Ujihira, Y.; Okabe, Y.; Sugano, T.; Niki, E. Ion-Sensitive Field-Effect Transistors with Inorganic Gate Oxide for pH Sensing. IEEE Trans. Electron Devices 1982, 29, 1936-1941.

(39)Field, R. J.; Winfree, A. T. Traveling Waves of Chemical Activity in the ZaikinZhabotinskii-Winfree Reagent. J. Chem. Educ. 1979, 56, 754.

(40)Nishida, H.; Kajisa, T.; Miyazawa, Y.; Tabuse, Y.; Yoda, T.; Takeyama, H.; Kambara, H.; Sakata, T. Self-Oriented Immobilization of DNA Polymerase Tagged by TitaniumBinding Peptide Motif. Langmuir 2015, 31, 732-740.

(41)Fujita, A.; Masuda, T.; Nishitani, S.; Akimoto, A. M.; Yoshida, R.; Sakata, T. Slow-PhaseTransition Behavior of Thermoresponsive Polymer Brushes Constrained at Substrate Observed by In Situ Electrical Monitoring Using poly( $N$-isopropylacrylamide)-Grafted Gate Field-Effect Transistor. Chem. Lett. 2021, in press.

(42)Uematsu, Y.; Kajisa, T.; Sakata, T. Fundamental Characteristics of Glucose Transistor with Chemically Functional Interface. ChemElectroChem 2017, 4, 2225-2231. 
(43)Kajisa, T.; Li, W.; Michinobu, T.; Sakata, T. Well-Designed Dopamine-Imprinted Polymer Interface for Selective and Quantitative Dopamine Detection among Catecholamines using a Potentiometric Biosensor. Biosens. Bioelectron. 2018, 117, 810817. 
For Table of Contents Only

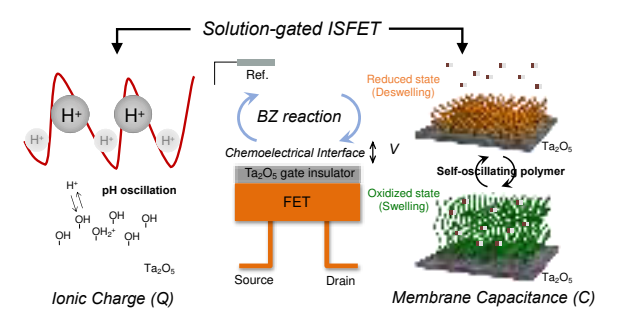




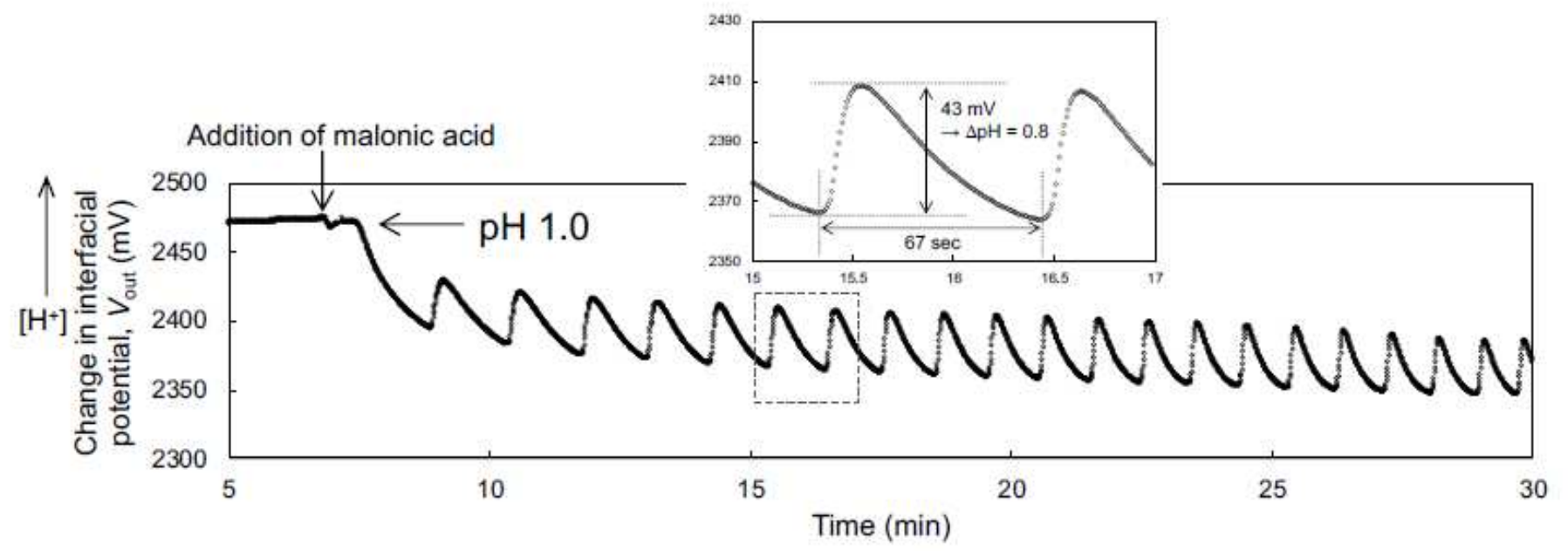

Figure 1

Change in interfacial potential (AVout) for BZ reaction detected using single-gate ISFET sensor. Malonic acid was added to the $\mathrm{BZ}$ presolution without malonic acid $(\mathrm{pH} 1.0)$. AVout was translated to $\mathrm{pH}$ in accordance with the $\mathrm{pH}$ sensitivity of the ISFET sensor (i.e., the Nernstian response) used in this study (Figure S1). 


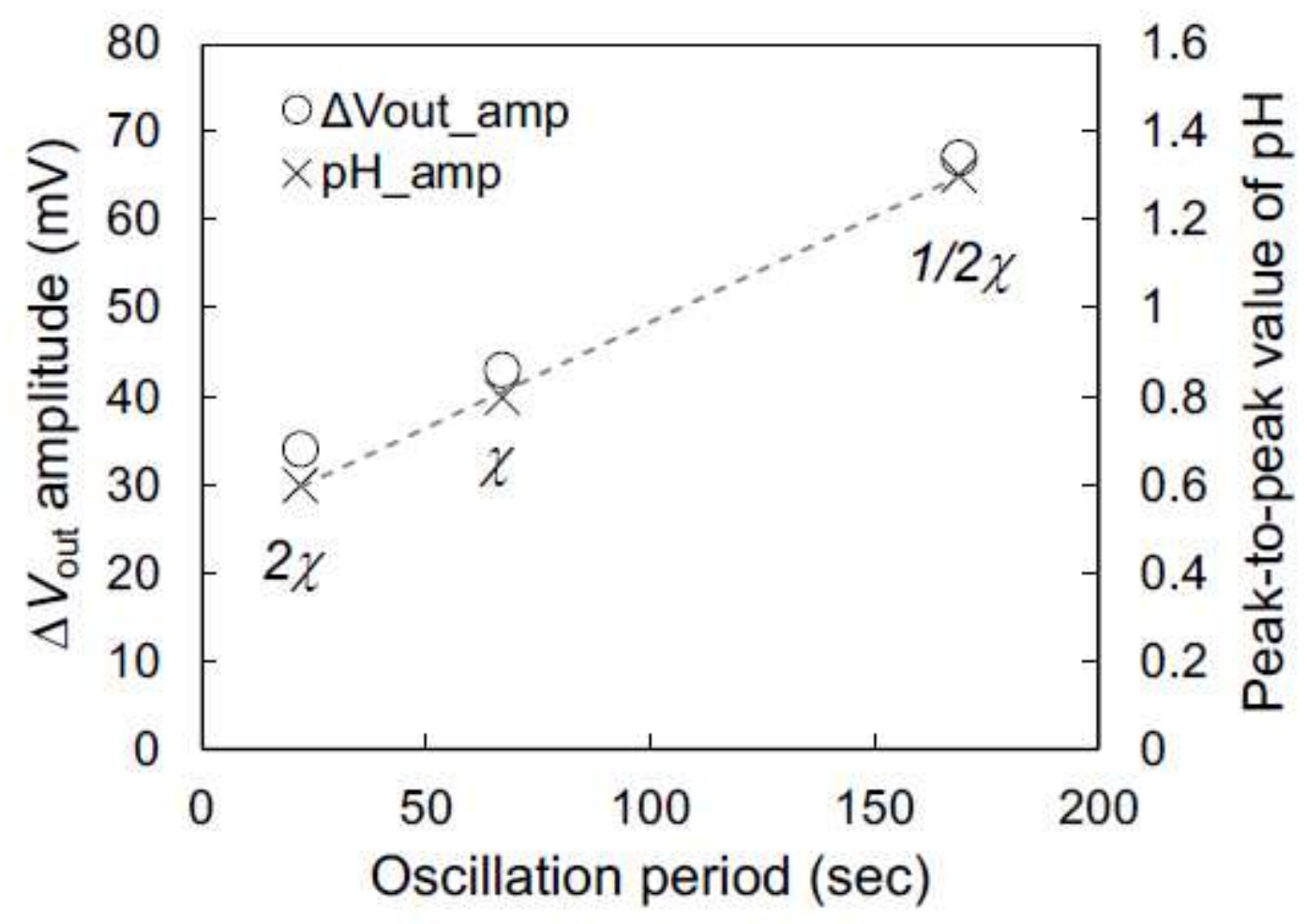

Figure 2

Peak-to-peak potential and $\mathrm{pH}$ (amplitude) for oscillation period based on Figures 1 and $\mathrm{S} 2$. The concentration $x$ of $B Z$ solution was controlled to $1 / 2 x, x$, and $2 x$. 


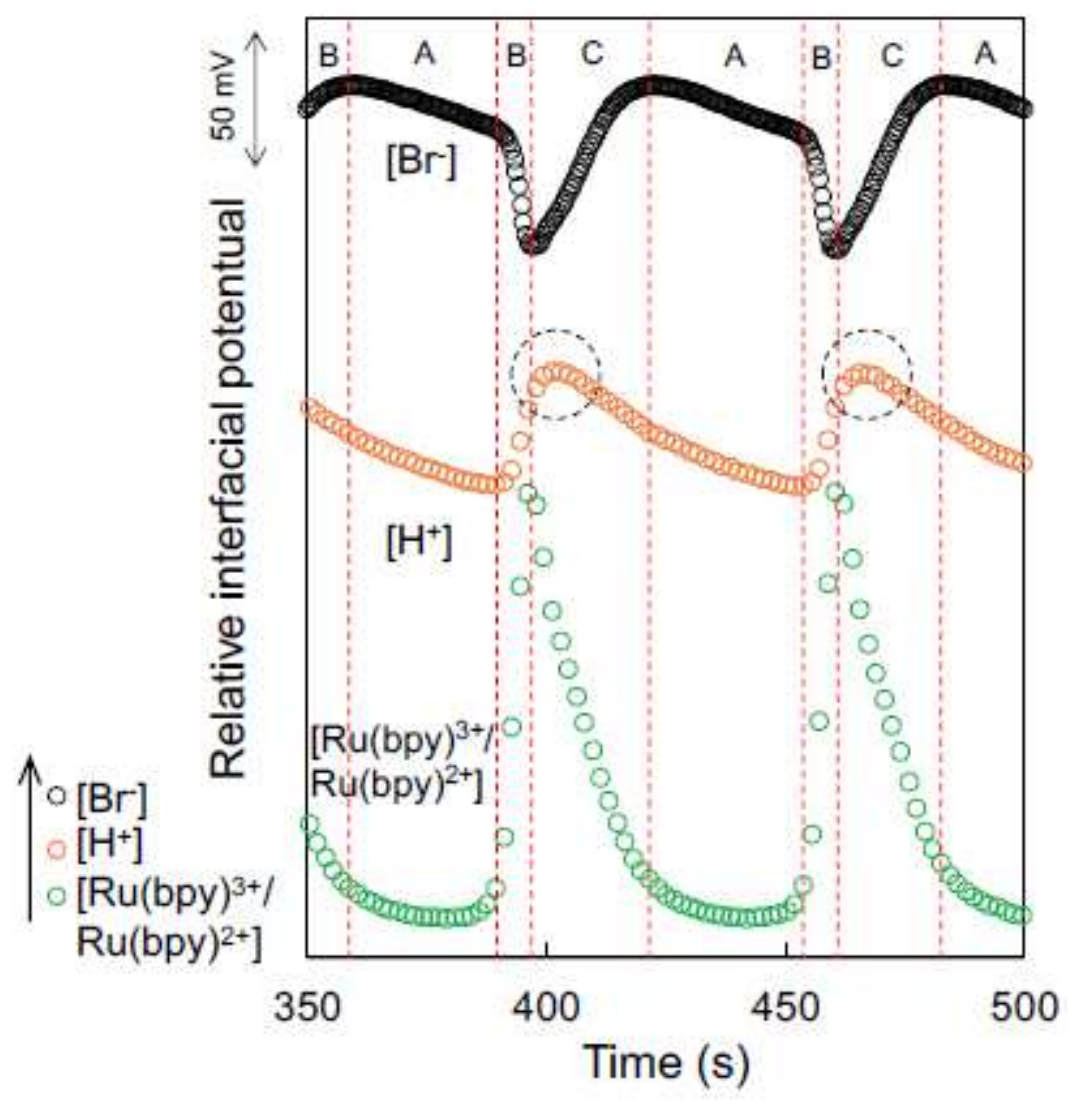

Figure 3

Self-oscillation behaviors of $[\mathrm{H}+]$, $[\mathrm{Ru}(\mathrm{bpy}) 3+/ \mathrm{Ru}(\mathrm{bpy}) 2+]$, and $[\mathrm{Br}-]$ based on relative interfacial potential. The durations of Processes A, B, and C based on the FKN mechanism (Table S2) are delineated by the dotted lines (red). The dotted circle (black) shows the position of the peak $[\mathrm{H}+]$. 


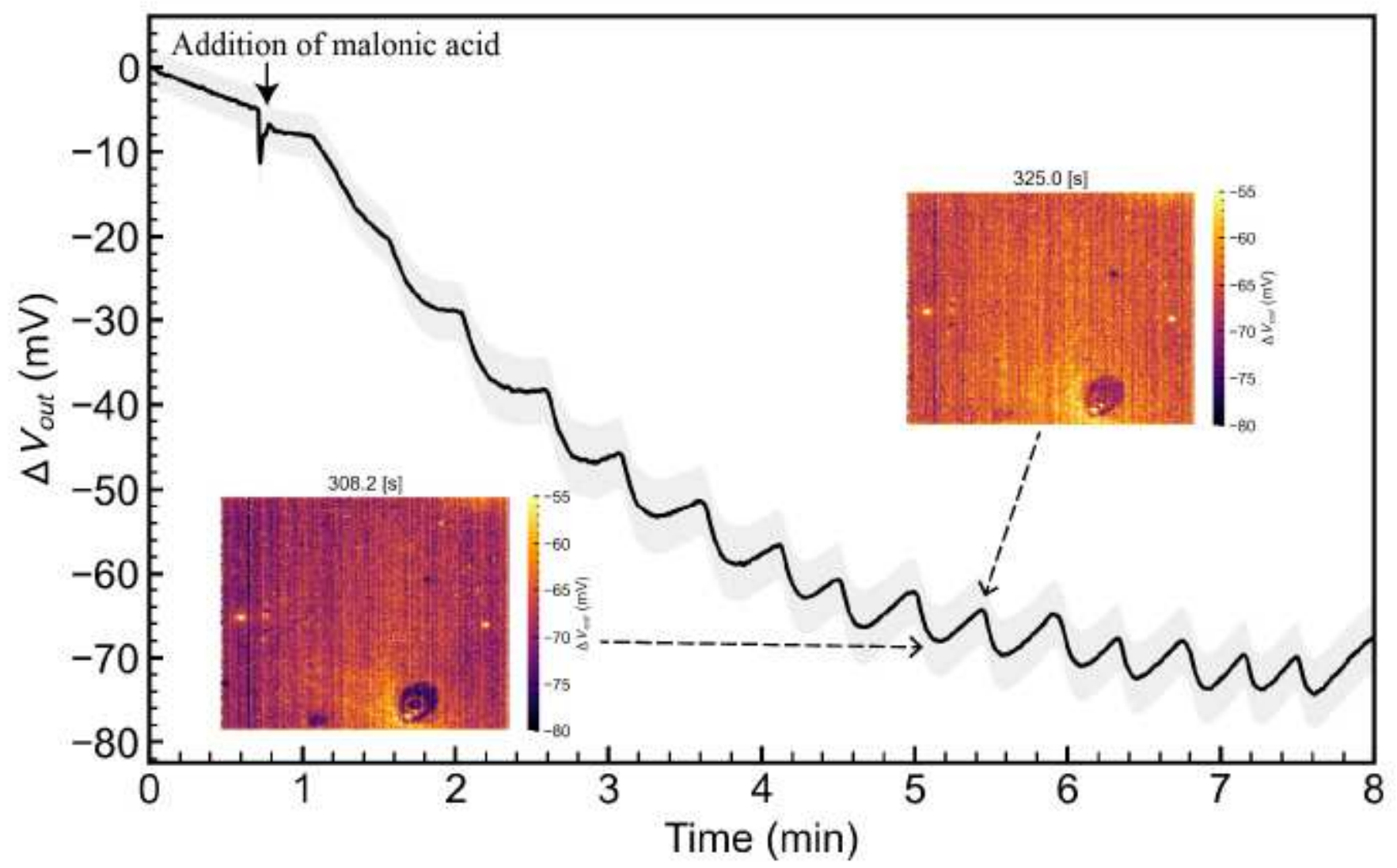

Figure 4

$\mathrm{pH}$ oscillation behavior on arrayed-gate ISFET sensor. AVout was output for $\mathrm{pH}$ analysis. The grey band around the line graph shows the standard errors for the $256 \times 256$ ISFETs except for $0.5 \%$ electrical failures.
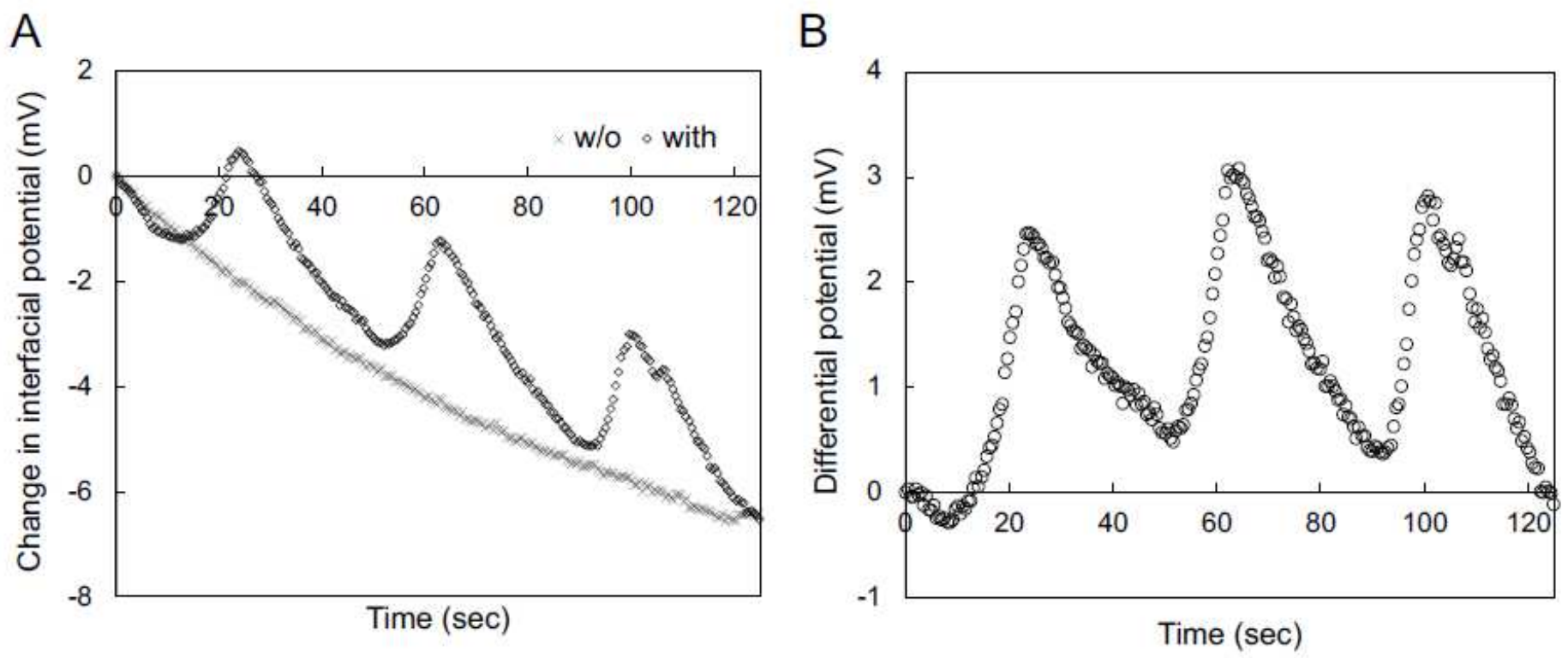
Figure 5

Electrical monitoring of self-oscillating polymer brush grafted on Ta205 gate insulator using single-gate ISFET sensor. (A) Electrical signals for single-gate ISFET sensors with and without self-oscillating polymer brush. (B) Differential signal based on (A).

\section{Supplementary Files}

This is a list of supplementary files associated with this preprint. Click to download.

- 112421SIBZpH.docx

- FigureS5.mp4

- TOC.pdf

- Scheme1.pdf 